\title{
Belief-Overkill in Political Judgments
}

\section{JONATHAN BARON}

\author{
Department of Psychology \\ University of Pennsylvania \\ 3720 Walnut St. \\ Philadelphia, PA 19104-6241 \\ U.S.A.
}

\section{baron@psych.upenn.edu}

Résumé: Lorsque des gens sont portées à prendre une décision politique, telle que voter pour le parti Républicain, c'est souvent seulement un seul sujet, tel que la position du parti sur l'avortement, qui les attire. Mais ensuite elles concluent que les autres politiques du parti, telles que celles sur les impôts, appuient leurs décisions. J'illustre ce phéno-mène avec l'aide de données tirées de sondages et d'une expérience réalisée sur l'Internet avec des candidats politiques hypothétiques. Les jugements qu'une politique d'un candidat hypo-thétique favorise celui-ci ou son adversaire sont mis en corrélation avec d'autres jugements sur les autres politiques du candidat. Cet effet est plus large parmi les sujets qui portent rarement des jugements opposés dans lesquels une poli-tique favorise un sujet et une autre politique favorise son adversaire. Dans quelques cas une politique qui se prononce contre un candidat vient à le favoriser. De tels changements en faveur d'un candidat sont plus probables lorsque le candidat est autrement favorisé. Cette expér-ience démontre une tendance à orienter tous les arguments vers une conclusion préférée.

Keywords: belief overkill, political judgment, myside bias, dominance structure, differentiationconsolidation theory, cognitive dissonance

(C) Jonathan Baron. Informal Logic, Vol. 29, No. 4 (2009), pp. 368-378. 


\section{Introduction}

Particularly since the 1973 Roe v. Wade decision in which the United States Supreme Court effectively legalized abortion in the U.S., the Republican Party has steadily increased its opposition to abortion and, more generally, its support of conservative religious views about social issues such as homosexuality, stem-cell research, and prayer. The Party has not, however, given up its long-standing support of self-reliance and its suspicions about government regulation, high taxes, and the use of tax money to help the poor. American conservatism has thus taken on a two-dimensional character, with "social conservatives" aligned with "economic conservatives." (See Layman, 1997, 1999, for examples of the extensive

literature on this subject.) It is difficult to see a clear connection between, say, opposition to high taxes for the rich, on the one hand, and opposition to abortion, on the other. ${ }^{1}$

It has struck many observers, and the author in particular, that Republican voters initially attracted to the Party by its stand on social issues came eventually to take on its economic positions too. Table 1 illustrates the change between 1972 and 2004. It shows correlations between the few relevant questions that were included in both surveys. The questions are listed in the Appendix. (Note that the "Party" question was scored as a dichotomy, so all correlations with that question are pointbiserial.) Correlations are generally low because single items like these have low reliability. Of course, with large samples, even tiny correlations are statistically significant (2705 for 1972, 1212 for 2004, but some data were missing for each item). Of interest is the act that the correlations between abortion - the sole socialconservatism item - and the two economic items (jobs and health-insurance) is essentially zero in 1972 but positive in 2004 ( $p<.001$ for the change for jobs, n.s., for health-insurance, but significant $[\mathrm{p}<.002]$ only for 2004). Moreover, the correlation of abortion with party affiliation is also essentially zero in 1972 but positive in 2004 ( $p<.001$ for the change). These results suggest that anti-abortion voters increasingly identified themselves as Republicans and tended to accept other positions of the Republican Party as a result, positions about which they would have been neutral but for their decision to support the Party.

This convergence of attitudes can be explained in terms of "belief overkill," a term that Jervis (1976) used in the context of how governments react to international conflicts. In essence, when some decision is salient, once people move toward an option, they try to bring their beliefs into line so that none of their beliefs oppose the favored option. For example, in discussions of a ban on testing nuclear weapons, "People who favored a nuclear test-ban believed that testing created a serious medical danger, would not lead to major weapons improvements, and was a source of international tension. Those who opposed the treaty usually took the

\footnotetext{
${ }^{1}$ It could even be argued that opposition to abortion and concern for the poor are both consistent with an attitude of sympathy toward those who are vulnerable. It is possible to make the opposite connection by thinking of the prohibition of abortion as a way of holding people responsible for their behavior. But this argument would not easily fit with some of the other attitudes that are generally correlated with anti-abortion attitudes, such as support for prayer in public schools.
} 
opposite position on all three issues. Yet neither logic nor experience indicates that there should be any such relationship. The health risks of testing are in no way connected with the military advantages, and a priori we should not expect any correlation between people's views on these questions" (Jervis, 1976, pp. 128-142). Ellsworth and Ross (1983) provide another example from attitudes about capital punishment: those who think that it is inherently immoral also think that it does not deter crime, and those who think it morally justified as retribution also think it deters.

Belief overkill is of course closely related to many other phenomena, such as cognitive dissonance (Festinger, 1962) and "myside bias" (Baron, 1995), of which it is an example, differentiation-consolidation theory (Svenson, 1992, 2006), constraint satisfaction (Simon, Krawczyk, \& Holyoak, 2004), the search for "dominance structures" (Montgomery, 1983), and information distortion (Russo, Medvec, \& Meloy, 1996).

In general, belief overkill may be understood as a form of self-deception (Baron, 2008), which in turn can be understood as a type of wishful thinking, an effect of desires on beliefs. Self-deception may be intentional or automatic. It may result from taking some action (or inaction) that would have the effect of manipulating one's own belief, and then not adjusting the strength of the belief to take into account the fact of the manipulation (Lord, Ross and Lepper, 1979; Mele, 1997; Silver, Sabini, \& Miceli, 1989). For example, an opponent of abortion, wanting to avoid inconsistency toward a candidate who opposes abortion and favors tax increases, could try to think of reasons why taxes needed to be increased. Then, presenting herself with those reasons as if they had resulted from an unbiased search, change her attitude so as to favor tax increases and thus to see the candidate's position as a strength. She would not discount her new belief to take into account the fact that her search for reasons was biased, designed to find reasons on one side but not the other.

The study I report here does not attempt to distinguish the various psychological mechanisms that might, or might not, account for belief overkill. Rather, it will apply (what I think is) a somewhat new method to the study of belief-overkill in political judgments. I gave subjects two positions of a political candidate and asked for an overall judgment of the candidate based on these position, and, critically, a judgment about how each position affected the candidate's attractiveness. The main prediction is that the subject's attitude toward one issue will predict evaluation of the other. To assess this relationship, I presented all possible pairs of issues of two types (moral and non-moral), and to predict the judgment of one issue I used the judgments of the second issue from all other pairs, not including the one at issue. This was to avoid the possibility that a relationship could result from a mere tendency to give the same answer to two successive questions.

The method is similar to that used by Lord et al. (1979), who also asked subjects about individual arguments (pieces of evidence) after presenting each one. Lord et al. showed that the evaluation of evidence as favoring or opposing the deterrent effect of capital punishment was influenced by the subject's prior attitude toward capital punishment. They called this effect, "biased assimilation." The present study differs from theirs in using very brief pieces of evidence - statements about a candidate's position on an issue - and, more importantly, in that it does not 
rely on any prior opinion about the candidate. The candidates are all hypothetical, and any opinion about the candidate is created on the spot from the evidence presented.

Table 1: Correlations between relevant questions common to 1972 and 2004 American National Election Study data. Positive numbers are more "conservative" (e.g., Republican party, anti-abortion, anti-health-insurance).

\begin{tabular}{|l|l|c|l|l|}
\hline \multicolumn{2}{|l|}{} & Party & Health Insurance & Jobs \\
\hline 1972 & Health Insurance & 0.195 & & \\
& Jobs & 0.206 & 0.331 & \\
& Abortion & -0.050 & 0.063 & -0.025 \\
\hline 2004 & Health Insurance & 0.374 & & \\
& Jobs & 0.463 & 0.497 & \\
& Abortion & 0.192 & 0.101 & 0.119 \\
\hline
\end{tabular}

\section{Experiment}

The question of interest was whether the candidate's position on one issue would affect the issue judgment for the other issue. If, for example, the abortion issue led them to favor candidate 1 , would they then also be inclined to say that the positions of the candidates on the inheritance tax also favored candidate 1 , even if, in other cases, they said that this issue favored candidate 2? In general, the hypothesis is that the subject's judgment of one issue will affect the judgment of the candidate, and this judgment, in turn, will affect the judgment of the other issue, so that it agrees with the judgment of the candidate. These effects can occur in either direction, or both directions. The reason for this effect is, arguably, the desire to avoid inconsistency, in which a candidate is favored despite contradictory evidence.

Such effects are easily explained in terms of the desire for consistency and its effect on self-deception, as explained above. In principle, they might also be understood in terms of presentation strategies. However, in this experiment, the subjects have no particular reason to convince the experimenter or anyone else to support a hypothetical candidate who has conflicting positions about issues that the subject cares about. It seems easier to explain the expected results in terms of the subjects' manipulation of their own judgments about issues.

In the experiment, each subject saw positions of two candidates on each of two issues. One issue was a "moral" issue such as abortion and other was non-moral. Candidate 1 was on the conservative side of the moral issue and also on the liberal side of the non-moral issue (e.g., favoring redistribution from rich to poor). Candidate 2 was on the other side of each issue. (For half of the subjects, the candidates were reversed, but I shall continue to refer to them this way.) The subjects then answered three questions. The first was about their candidate preference. The two others, which I call position judgments, were about the effect 
of each issue on their preference, specifically, whether the candidates' positions on that issue led them to favor candidate 1 or $2 .^{2}$

\subsection{Method}

A questionnaire was presented on the World Wide Web. Each subject received $\$ 4$ for completing it (paid through PayPal, along with payments for other studies). It was completed shortly after the 2004 U.S. election by 171 subjects, ranging in age from 21 to 77 (median 41); 20\% were male. Two others were omitted because they gave the same response to all questions. Subjects were from a panel of about 1,500 that completed questionnaires on the World Wide Web for pay; most members of the panel found the opportunity on the Web by looking for ways to make money. Although the present study did not ask about income or education, other studies found panel members to have about the same median income and education as Americans on the whole (although less variance in income). Most subjects were in the U.S.

The questionnaire began, "In real elections, candidates sometimes don't follow their 'party line.' This study is about hypothetical choices between candidates for national office in the U.S. In each case, please imagine that two candidates hold the same position on most issues you care about, and these positions are acceptable to you. The candidates differ on a couple of issues." After this, each subject saw 36 pages, with answers required on each before the next was shown. The 36 pages, presented in a random order chosen for each subject, represented all possible combinations of conflicting positions. Thus, each issue was presented 6 times. A typical page was:

Candidate 1 favors a constitutional amendment defining marriage as between a man and a woman and favors increased income taxes on those with high incomes, to reduce the deficit.

Candidate 2 opposes a constitutional amendment defining marriage as between a man and a woman and opposes increased income taxes on those with high incomes, to reduce the deficit.

What is your position on the two candidates (assuming they both have equally acceptable positions on everything else you care about)?

Strongly favor Candidate 1

Favor Candidate 1

Neutral

Favor Candidate 2

Strongly favor Candidate 2

\footnotetext{
${ }^{2}$ I did a second experiment in which each page had only one candidate. The results were consistent with those I report but added nothing new.
} 
What is the effect of the candidates' position on a constitutional amendment defining marriage as between a man and a woman on your evaluation of the two candidates?

Strongly favors Candidate $1 \ldots$

[The same question was asked about the other issue.]

I shall call these the position judgments (as opposed the candidate evaluation). The words "favors" and "opposes" and the issues were highlighted with different colors. For half of the subjects the moral issue came first, and for half the nonmoral issue came first (and candidate two took the place of candidate 1). ${ }^{3}$

The moral items were (with candidate 1's position):

- favors a constitutional amendment defining marriage as between a man and a woman;

- favors a national ban on third-trimester abortions for any reason;

- opposes appointment of pro-choice Supreme Court judges committed to keeping Roe v. Wade;

- favors teaching creationism in schools;

- opposes U.S. funding for stem-cell research with new cell lines (currently prohibited);

- opposes appointment of Supreme Court judges who favor affirmative action.

The non-moral items were (with candidate 1's position):

- favors increased income taxes on those with high incomes, to reduce the deficit;

- opposes ending the inheritance tax;

- favors a national program to provide health insurance for those without it;

- favors increased national fuel-efficiency standards for cars;

- favors signing the Kyoto protocol, committing the U.S. to reduce emissions of carbon dioxide;

- opposes caps on punitive damages in malpractice lawsuits.

\subsection{Results}

As hypothesized, judgments about whether one position helped or hurt a candidate (position judgments) were related to subjects' attitudes about the other issue, as determined from other hypothetical candidates. ${ }^{4}$

The simple test of this belief-overkill hypothesis is to ask whether the position judgment of one issue correlated with the position judgment of the other issue. However, it is possible that such a correlation could arise from a simple tendency to repeat the same response or, more generally, from a tendency to assimilate adjacent

\footnotetext{
${ }^{3}$ The second half of the subjects were tested a few weeks later when I realized that the first half was not counterbalanced.

${ }^{4}$ On a scale of -2 to 2 , where 2 represents agreement, the means were 0.12 for the moral issues and 0.42 for the non-moral issues, with standard deviations of 1.52 and 1.28 , respectively.
} 
judgments to each other. To avoid this effect, I calculated the sum of the position judgments across the six presentations of each issue to each subject. Then I subtracted from this sum the position judgment for the page in question and used result as the predictor. In other words, the predictor is the sum of all the ratings of the same issue except the rating on the same page. All responses were scaled so that the neutral point was zero, and positive ratings favored the conservative position; the scale was thus -2 to 2 .

To test the correlation between the belief judgment of one issue and the belief judgment of the other (from five other pages), I used a mixed model with crossed random effects (specifically, the lmer function in Bates \& Maechler, 2009, and the pvals.fnc function in Baayen, 2008) to assess reliability. Specifically, the dependent variable was the rating of one position, and the belief judgment of the other (from the five other pages) was the single fixed effect. Random effects were included for subject, issue, the slope of the predictor for each subject, and the slope of the predictor for each case.

Baayen, Davidson, and Bates (2008) describe how this approach overcomes the dilemma posed by the "language-as-fixed-effect fallacy," where researchers have a choice of testing across items or subjects (Clark, 1973). By including both subject and item as random effects, we get a single overall test. In the analysis I report, I used the most conservative approach, which was to include a fixed effect for the position rating (from other cases), and random effect terms for subjects, for the six moral items, for the six non-moral items, and for the three slopes of position rating in the first three random terms. This approach is equivalent to showing that the effects generalize across both subjects and items, assuming that subjects and items are random samples from some population. The final tests were done after removal of non-significant (95\% confidence) random-effect terms, using 100,000 Markov-chain-Monte-Carlo (MCMC) samples. Less conservative approaches (in particular, eliminating the random slopes for the non-moral and moral items) led to much lower p-values. Less conservative approaches would be justified by thinking of the tests of interest as one-tailed (Baron, 2010). ${ }^{5}$

In the main analysis of belief overkill, the estimated coefficient for the effect of the non-moral position on the moral position ratings was $0.011(\mathrm{p}=.0507$, two tailed). This is a small effect: on the average the rating increased by 0.011 units on the 5-point scale with every unit change in the predictor (on the same scale). The effect of the moral position on the non-moral position was higher: $.094(p=.0011){ }^{6}$ These two results together make a strong case for a small effect. A small effect is all that is required by the present hypothesis. Many subjects do not engage in belief overkill (as I explain later), or have such strong attitudes that they are impervious to these effects.

\footnotetext{
${ }^{5}$ In this sort of analysis, it is possible to derive a t statistic for each predictor, but it is not possible to determine clearly the degrees of freedom for this statistic. Thus, a simulation approach is recommended, using MCMC sampling, based on a Bayesian model, in which the analysis is essentially repeated many times, and the posterior distribution of each parameter is examined. The $\mathrm{p}$-value reported is essentially the area of this posterior distribution that falls on the wrong side of zero, i.e., no effect. See Baayen et al. (2008) for discussion.

6 The moral and non-moral positions were not equated in any way, so we cannot draw any general conclusion from the apparent difference between them.
} 
A second analysis looked at reversals, in which the sign of the position judgment was opposite to the sign of the judgments of the same position for the other five cases. Reversals involving the moral position judgment were predicted by the other five cases of the non-moral judgment $(p=.0215$, using a mixed model predicting reversals from the mean judgment of the other issue, with random effects for subjects and issues, and random slopes for the effects), and reversals involving the non-moral judgment were predicted by the other five cases of the moral judgment $(p=.0032)$. These effects were also quite small, as there were few reversals (less than 6\%).

Reversals were also predicted by judgments about the candidate (the first question). The more favorable the candidate's rating, the more likely it was that the position judgments would be positive when, for other candidates, the same position judgments would be (on the average) negative ( $p=.0001$, using the same mixedmodel approach as earlier). When a candidate was strongly favored, $83 \%$ of the reversals were favorable to that candidate. (Only 3\% of all the cases involved such reversals, however.)

Importantly, subjects differed in their willingness to accept conflict. I measured this by looking at the proportion of cases in which the position judgments had opposite signs within a page. (Note that the cases were designed so that the positions always conflicted in terms of the recent election, so we might expect some subjects to have a conflict on every page.) The mean conflict score was 0.33 . Thus, despite the fact that we might expect frequent conflict, it occurred only $1 / 3$ of the time. Individual differences were striking. The conflict scores ranged from 0 (no conflict) to 1 , with a standard deviation of .27 , and a range between .07 for the 25 th percentile to .56 for the 75 th.

Subjects who accepted less conflict showed a larger belief-overkill effect. To measure the overkill effect for each subject, I multiplied two measures: the deviation of each position judgment from the mean of the other five judgments of the same position; and the mean of the other five judgments of the other position. Because these measures were all centered at zero, a positive sum of all of them (both positions) would indicate a belief-overkill effect, that is, a relation between one position judgment (outside of the current case) and the deviation of the other position judgment from its normal level. The subject means of these overkill measures correlated negatively (as predicted) with the conflict scores, but the correlation was not quite significant $(\mathrm{r}=-.15, \mathrm{p}=.058)$. However, it turned out that conflict scores were also correlated with time spent on the task (as measured by the logarithm of the mean time of the fastest half of the pages); evidently, subjects who went faster were more inclined to give the same or similar position judgments. When the overkill measure was regressed on both time and conflict scores, the effect of conflict was highly significant (effect $-0.14, p=.0058$ ). These results suggest that subjects differed in their tolerance for conflict about the positions of a candidate, and those with the least tolerance were more likely to engage in belief overkill. 


\section{Discussion}

Political judgments made by citizens are almost necessarily compromises because we have limited choice. We choose among a small number of bundles of positions, pre-packaged. These positions can be described in terms of various dimensions, but the number of dimensions is large: autonomy vs. paternalism; free enterprise vs. regulation; free enterprise vs. government provision; internationalism vs. isolationism; individual responsibility vs. sympathy for those who fail; judicial conservatism vs. activism; large vs. small government; environmental conservation vs. development; and so on. At a given point in history, in a given nation, a few of these issues may dominate the political discussion, so that it is possible for citizens to adopt clear stances in which all the issues point in one direction. But this is rare. For example, the U.S. elections of 2000 and 2004 seemed about as clear as any, yet the author, who voted for the Democratic candidate both times, favored some Republican positions (limitation of tort liability; free trade; school vouchers).

People seem to differ in the extent to which they can tolerate such conflict. Some will say, "On balance, given the choice I have, Candidate $\mathrm{X}$ is better than Candidate Y because I agree with X on the issues that I see as more important." Others will find such conflict frustrating and change their positions, "Maybe free trade isn't such a clear issue after all." The methods used here could be useful as measures of individual differences in the tendency to achieve consistent judgments. These may related to differences in other measures of thinking styles, such as those studied by Stanovich and West (1998) or Baron (1995). They could also be malleable through education.

Possibly these differences arise from argumentation strategies. People may think of their role as citizens in terms of persuading others rather than making decisions, and some may think that others are most persuaded when all the arguments are on one side (Baron, 1991, 1995). They may also think that better thinkers are more sure, with no conflict. Insofar as they think about argumentation, they may be deluding themselves. Most political argumentation seems more designed to elicit action in those who already agree rather than to change anyone's mind. And many people may be more easily persuaded by someone who acknowledges arguments on the other side.

\section{Acknowledgements}

I thank Hal Pashler, Lance Rips and two anonymous reviewers for helpful comments. The work was supported by a grant from the U.S.Israel Bi-national Science Foundation to J. Baron and I. Ritov. 


\section{References}

Baayen, R. H. (2008). languageR: Data sets and functions with "Analyzing Linguistic Data: A practical introduction to statistics". R package version 0.953.

Baayen, R. H., Davidson, D. J., \& Bates, D. M. (2008). Mixed-effect modeling with crossed random effects for subjects and items. Journal of Memory and Language, 59, 390-412.

Baron, J. (1991). Beliefs about thinking. In J. F. Voss, D. N. Perkins, \& J. W. Segal (Eds.), Informal reasoning and education, pp. 169-186. Hillsdale, NJ: Erlbaum.

Baron, J. (1995). Myside bias in thinking about abortion. Thinking and Reasoning, $1,221-235$.

Baron, J. (2008). Thinking and deciding (4th ed.). New York: Cambridge University Press.

Baron, J. (2009). Looking at individual subjects in research on judgment and decision making (or anything). Acta Psychologica Sinica, 42, 1-11.

Bates, D. \& Maechler, M. (2009). lme4: Linear mixed-effects models using S4 classes. R package version 0.999375-31.

Ellsworth, P. C., \& Ross, L. (1983). Public opinion and capital punishment: A close examination of the views of abolitionists and retentionists. Crime and Delinquency, 29, 116-169.

Festinger, L. (1962). Cognitive dissonance. Scientific American, 107 (4).

Jervis, R. (1976). Perception and misperception in international politics. Princeton: Princeton University Press.

Layman, G. C. (1997). Religion and political behavior in the United States: The impact of beliefs, affiliation and commitment from 1980 to 1994. Public Opinion Quarterly, 61, 288-316.

Layman, G. C. (1999). "Culture wars" in the American party system: Religious and cultural change among party activists since 1972. American Politics Research, $27,89-121$.

Lord, C. G., Ross, L., \& Lepper, M. R. (1979). Biased assimilation and attitude polarization: The effects of prior theories on subsequently considered evidence. Journal of Personality and Social Psychology, 37, 2098-2109.

Mele, A. R. (1997). Real self-deception. Behavioral and Brain Sciences, 20, 91102.

Montgomery, H. (1983). Decision rules and the search for a dominance structure: Towards a process model of decision making. In P. C. Humphreys, O. Svenson \& A. Vari (Eds) Analyzing and aiding decision processes, pp. 343-369. Amsterdam: North Holland.

Russo, J. E., Medvec, V. H., \& Meloy, M. G. (1996). The distortion of information during decisions. Organizational Behavior and Human Decision Processes, 66, 102-110.

Sapiro, V., Rosenstone, S. J., and the National Election Studies. AMERICAN NATIONAL ELECTION STUDIES CUMULATIVE DATA FILE, 1948-2004 [Computer file]. ICPSR08475-v13. Ann Arbor, MI: University of Michigan, Center for Political Studies [producer], 2004. Ann Arbor, MI: Inter- university 
Consortium for Political and Social Research [distributor], 2007-09-25. doi:10.3886/ICPSR08475

Silver, M., Sabini, J., \& Miceli, M. (1989). On knowing self-deception. Journal for the Theory of Social Behavior, 19, 213-227.

Simon, D., Krawczyk, D. C., \& Holyoak, K. J. (2004). Construction of preferences by constraint satisfaction. Psychological Science, 15, 331-336.

Stanovich, K. E., \&West, R. F. (1998). Individual differences in rational thought. Journal of Experimental Psychology: General, 127, 161-188.

Svenson, O. (1992). Differentiation and consolidation theory of human decision making: A frame of reference for the study of pre- and post-decision processes. Acta Psychologica, 80, 143-168.

Svenson, O. (2006). Pre- and post-decision construction of preferences: Differentiation and consolidation. In S. Lichtenstein \& P. Slovic, (Eds.) The construction of preference (pp. 356-371). Cambridge: Cambridge University Press.

\section{Appendix: Questions from American National Election Study}

The questions were roughly as follows. (Some wording was changed between the two surveys.)

The health-insurance question was "There is much concern about the rapid rise in medical and hospital costs. Some feel there should be a government insurance plan which would cover all medical and hospital expenses. Others feel that medical expenses should be paid by individuals, and through private insurance like Blue Cross. Where would you place yourself on this scale, or haven't you thought much about this?" (7-POINT SCALE)

The jobs question was "Some people feel that the government in Washington should see to it that every person has a job and a good standard of living. Others think the government should just let each person get ahead on his/their own. Where would you place yourself on this scale, or haven't you thought much about this?" (7-POINT SCALE)

The abortion question was, "There has been some discussion about abortion during recent years. Which one of the opinions on this page best agrees with your view?

1. Abortion should never be permitted.

2. Abortion should be permitted only if the life and health of the woman is in danger.

3. Abortion should be permitted if, due to personal reasons, the woman would have difficulty in caring for the child.

4. Abortion should never be forbidden, since one should not require a woman to have a child she doesn't want."

I coded party identification as Republican vs. Democrat, and all others were missing data. However, the correlations reported in Table 1 used all possible items for each correlation. 